\title{
Preliminary evaluation of endogenous milk fluorophores as tracer molecules for curd syneresis
}

\author{
C. C. Fagan, ${ }^{\star 1}$ T. G. Ferreira,† F. A. Payne,† C. P. O’Donnell, ${ }^{\star}$ D. J. O’Callaghan,‡ and M. Castillo†§ \\ *Biosystems Engineering, School of Agriculture, Food Science and Veterinary Medicine, University College Dublin, Belfield, Dublin 4, Ireland \\ †Department of Biosystems and Agricultural Engineering, University of Kentucky, $128 \mathrm{C}$. E. Barnhart Building, Lexington 40546-0276 \\ $\ddagger$ Moorepark Food Research Centre, Teagasc, Fermoy, Co. Cork, Ireland \\ $\S$ Department of Animal and Food Science, Universitat Autònoma de Barcelona, Edifici V, Campus de la UAB, 08193, Barcelona, Spain
}

\section{ABSTRACT}

A front-face fluorescence spectroscopy probe was installed in the wall of a laboratory-scale cheese vat. Excitation and emission filters were chosen for the selective detection of vitamin A, tryptophan, and riboflavin fluorescence. The evolution of the fluorescence of each fluorophore during milk coagulation and syneresis was monitored to determine if they had the potential to act as intrinsic tracers of syneresis and also coagulation. The fluorescence profiles for 2 of the fluorophores during coagulation could be divided into 3 sections relating to enzymatic hydrolysis of $\kappa$-casein, aggregation of casein micelles, and crosslinking. A parameter relating to coagulation kinetics was derived from the tryptophan and riboflavin profiles but this was not possible for the vitamin A response. The study also indicated that tryptophan and riboflavin may act as tracer molecules for syneresis, but this was not shown for vitamin A. The evolution of tryptophan and riboflavin fluorescence during syneresis followed a first-order reaction and had strong relationships with curd moisture and whey total solids content $(\mathrm{r}=0.86-0.96)$. Simple 1- and 2-parameter models were developed to predict curd moisture content, curd yield, and whey total solids using parameters derived from the sensor profiles (standard error of prediction $\left.=0.0005-0.394 \% ; \mathrm{R}^{2}=0.963-0.999\right)$. The results of this study highlight the potential of tryptophan and riboflavin to act as intrinsic tracer molecules for noninvasive inline monitoring of milk coagulation and curd syneresis. Further work is required to validate these findings under a wider range of processing conditions.

Key words: fluorescence spectroscopy, coagulation, syneresis, cheese

Received March 28, 2011.

Accepted May 2, 2011

${ }^{1}$ Corresponding author: colette.fagan@ucd.ie

\section{INTRODUCTION}

Development of a syneresis control technology is an emerging area of research due to the significant effect of syneresis on cheese quality and yield. Syneresis, a core mechanism in cheese making, is a complex process with multiple factors having an interactive effect on its rate and extent. Fagan et al. (2007b) reported that between 28 and $35^{\circ} \mathrm{C}$, a shorter cutting time and higher calcium chloride level maximized the retention of TS, CN, and fat, but decreased curd moisture content, whereas a later cutting time and lower calcium chloride level gave a lower retention of TS but increased the curd moisture content. Therefore, control of syneresis is desirable, as the quality of the curd at draining will ultimately influence the quality of the final product (Daviau et al., 2000).

Recently, online noninvasive sensing techniques have been investigated to monitor syneresis based on the changing optical properties of the mixture in the cheese vat during syneresis and its effect on the backscatter of near infrared light (Castillo et al., 2005a; Fagan et al., 2008a). They found it was possible to predict curd moisture content online during syneresis with standard error of prediction (SEP) in the range of 0.92 to $1.72 \%$ (wt/wt). However, traditionally, studies have used 1 of 2 approaches to monitor syneresis (i.e., separation and analysis of curd and whey; Pearse and Mackinlay, 1989) or dilution of added tracer molecules (Talens et al., 2009). In the tracer method, a chemical agent (e.g., Blue Dextran 2000; Sigma Aldrich Ireland Ltd., Dublin, Ireland) is added to the curd and whey mixture where it is logarithmically diluted as whey is expelled and the rate at which this occurs indicates the rate of syneresis. However the chemical agent must not be toxic, should not affect syneresis, or be adsorbed onto the surface of the curd or diffuse into it. The potential of intrinsic compounds to act as tracer molecules has had limited study. Castillo et al. (2005b) found that an optical sensor had potential to measure whey fat concentration, thereby indicating that whey fat globules could potentially be used as an intrinsic tracer molecule 
for syneresis. However, to date, no study has examined the potential of intrinsic fluorescent compounds in milk to act as tracer molecules during syneresis.

Several intrinsic fluorescent compounds exist in milk and fluorescence spectroscopy can provide information on their presence and physical environment in which they exist. For example, the relatively increased exposure of tryptophan toward more hydrophilic surroundings tends to result in a shift in the maximum emission peak toward a lower wavelength. Fluorescence spectroscopy has been widely used to characterize a range of dairy products (Christensen et al., 2003; Andersen and Mortensen, 2008). Herbert et al. (2000) used tryptophan and vitamin A fluorescence spectra in conjunction with chemometric techniques to discriminate between soft cheeses, resulting in classification rates greater than 90\%. Fluorescence spectroscopy has also been used to monitor changes in milk powder during manufacture and storage (Liu and Metzger, 2007). They found that it was possible to detect changes due to the Maillard reaction, modification of the tryptophan environment, and degradation of riboflavin. Herbert et al. (1999) monitored the evolution of tryptophan fluorescence resulting from milk coagulation in a $1 \times$ $1 \mathrm{~cm}$ quartz cuvette. They stated that it was possible to detect stages of coagulation and differences between gels with varying rheological characteristics. However, currently, no study has investigated the potential of fluorescence spectroscopy to monitor coagulation and syneresis online in a laboratory-scale cheese vat.

Vitamin A compounds are lipid soluble and make up $6 \times 10^{-4}$ to $9 \times 10^{-4} \%$ of total milk lipids. They are mostly located in the hydrophobic core of the fat globule, with a certain amount associated with the fat globule membrane (Zahar et al., 1995). They can be sensitive to processing conditions such as severity of heating, storage history, package material, and fat content (Öste et al., 1997). However heating milk at temperatures less than $100^{\circ} \mathrm{C}$ has been shown to have a minor effect on vitamin A content (Brinkmann et al., 1993; Wagner et al., 1993). It has also been stated that the fluorescence properties of vitamin A provide information about the physical state of triglycerides and protein-lipid interactions (Andersen and Mortensen, 2008).

Tryptophan is an essential AA abundant in milk protein (i.e., CN). It has a large extinction coefficient and is the dominant fluorescent AA. Fluorescence of tryptophan has been used to provide information on protein structure (Dufour et al., 2001; Karoui et al., 2005), as fluorescence depends on how tryptophan is exposed in the 3-dimensional configuration of the proteins (Andersen and Mortensen, 2008).
Riboflavin is a water-soluble vitamin, which can be a precursor to oxidation reactions (Liu and Metzger, 2007). Fluorescence spectroscopy has been used to monitor oxidative changes in riboflavin (Wold et al., 2002; Miquel Becker et al., 2003).

We hypothesize that the milk fluorophores vitamin A, tryptophan, and riboflavin may be used as intrinsic tracers of the syneresis process, as each will preferentially interact with certain phases and structures of the curd-whey mixture. The objective of this study was to determine the potential of 3 naturally occurring milk fluorophores (i.e., vitamin A, tryptophan, and riboflavin), to act as tracers of syneresis. A front-face fluorescence spectroscopy probe was installed in the wall of an 11-L cheese vat and the evolution of fluorescence of each compound was monitored during milk coagulation and syneresis.

\section{MATERIALS AND METHODS}

\section{Milk Preparation and Coagulation}

Unpasteurized and unhomogenized whole bovine milk was obtained from a local Kentucky milk processing plant (Winchester Farms Dairy, Winchester, KY). A $40-\mathrm{mL}$ representative sample of milk was removed for compositional analysis, using a MilkoScan FT 120 (Foss Electric, Hillerød, Denmark). A further $10.2 \mathrm{~kg}$ of the milk was weighed for use in each experiment and 3 mmol of $\mathrm{CaCl}_{2}$ was added and it was stirred for $3 \mathrm{~min}$ and then left to equilibrate for $30 \mathrm{~min}$ in a cold room at $2^{\circ} \mathrm{C}$. An 11-L cheese vat (Type CAL 10L; Pierre Guerin Technologies, Mauze, France), as described by Everard et al. (2008), was used in this study. The vat temperature was controlled via a heating jacket and a water bath having a control accuracy of $\pm 0.01^{\circ} \mathrm{C}$ (Lauda RM 20; Brinkman Instrument Inc., Westbury, NY). Ten kilograms of the prepared milk was added to the vat and left to equilibrate at the coagulation temperature $\left(32^{\circ} \mathrm{C}\right)$ under stirring at $26 \mathrm{rpm}$. Milk pH was recorded at $32^{\circ} \mathrm{C}$ to ensure that the milk $\mathrm{pH}$ was stable. Milk temperature was measured with a precision thermistor (model 5831 A; Omega Engineering Inc., Stamford, $\mathrm{CT}$; accuracy $\pm 0.2^{\circ} \mathrm{C}$ ). Chymosin enzyme [CHY-MAX Extra; Enzyme Commission (EC) 3.4.23.4 isozyme B, 643 international milk clotting units (IMCU)/mL; Chr. Hansen Inc., Milwaukee, WI] was used for milk coagulation. Once thermal equilibrium was achieved, chymosin was added to the milk at a level of $0.06 \mathrm{~mL} / \mathrm{kg}$ milk and stirred for $3 \mathrm{~min}$ at $31 \mathrm{rpm}$. Data acquisition for the fluorescence sensor commenced upon addition of the enzyme. Trials were carried out in triplicate for each filter configuration (Table 1). 
Table 1. Center wavelengths for excitation and emission filters used in the experiment

\begin{tabular}{lcc}
\hline Fluorophore & $\begin{array}{c}\text { Excitation } \\
\text { wavelength } \\
(\mathrm{nm})\end{array}$ & $\begin{array}{c}\text { Emission } \\
\text { wavelength } \\
(\mathrm{nm})\end{array}$ \\
\hline Vitamin A & 355.2 & 481.1 \\
Tryptophan & 281.3 & 340.6 \\
Riboflavin & 281.3 & 521.2 \\
\hline
\end{tabular}

\section{Online Fluorescence Monitoring Instrumentation}

A filter-based fluorometer (UV Photo-X Fluorescence System Model 53F; Custom Sensors \& Technology, Fenton, MO) was used to monitor changes in fluorescence during coagulation and syneresis. Appropriate excitation and emission filters (Semrock Inc., Rochester, NY) were chosen for detection of vitamin A, tryptophan, and riboflavin fluorescence as detailed in Table 1. In the fluorometer, a xenon flash lamp transmitted light for excitation through the excitation wavelength selection filter and into a fiber optic cable, which transferred the excitation light to the front-face fluorescence probe mounted in the wall of the cheese vat (Figure 1). The fluorescence probe transmitted the excitation light into the vat, and returned the resulting fluorescence from the sample through a fiber optic cable to the analyzer. The emission light passed through the emission filter to remove any residual excitation energy collected by the fluorescence probe. The emission light then impinged on the detector, and the resulting signal was transferred to a data acquisition system (CoAguLab; Reflectronics Inc., Lexington, KY). To zero the optical measuring system, light was excluded and the resulting voltage response was subtracted from all subsequently recorded data. Response data were collected every $6 \mathrm{~s}$. The initial voltage response ( $V_{0}$; average of the first minute of voltage data points form enzyme addition) was calculated by averaging the first 10 data points (i.e., first minute of collected data). A fluorescence intensity ratio $(R)$ was calculated by dividing the sensor output voltage at any time by $V_{0}$. The first derivative $\left(R^{\prime}\right)$ of the fluorescence intensity ratio profile was calculated by conducting linear least-squares regression on the most recently collected $4 \mathrm{~min}$ of data. The calculated slope was assigned to the midpoint of the data subset used.

\section{Cutting Time Selection and Gel Cutting Procedure}

Cutting time $\left(t_{c u t}\right)$ was visually determined by the operator. It was taken as time zero $\left(t_{0}\right)$ for all subsequent syneresis measurements. Cutting of the gel was achieved by the twin cutting blades of the vat. The gel was cut at a constant speed of $6 \mathrm{rpm}$ for $20 \mathrm{~s}$, then allowed to rest for $1 \mathrm{~min}$, cut a second time at a speed of $18 \mathrm{rpm}$ for $15 \mathrm{~s}$, allowed to rest for $1 \mathrm{~min}$, and cut a third time at a speed of $18 \mathrm{rpm}$ for $10 \mathrm{~s}$ and allowed to rest for $1 \mathrm{~min}$, followed by stirring at $12 \mathrm{rpm}$ for $85 \mathrm{~min}$ (i.e., up to $t_{85}$ ). This procedure was adapted from Fagan

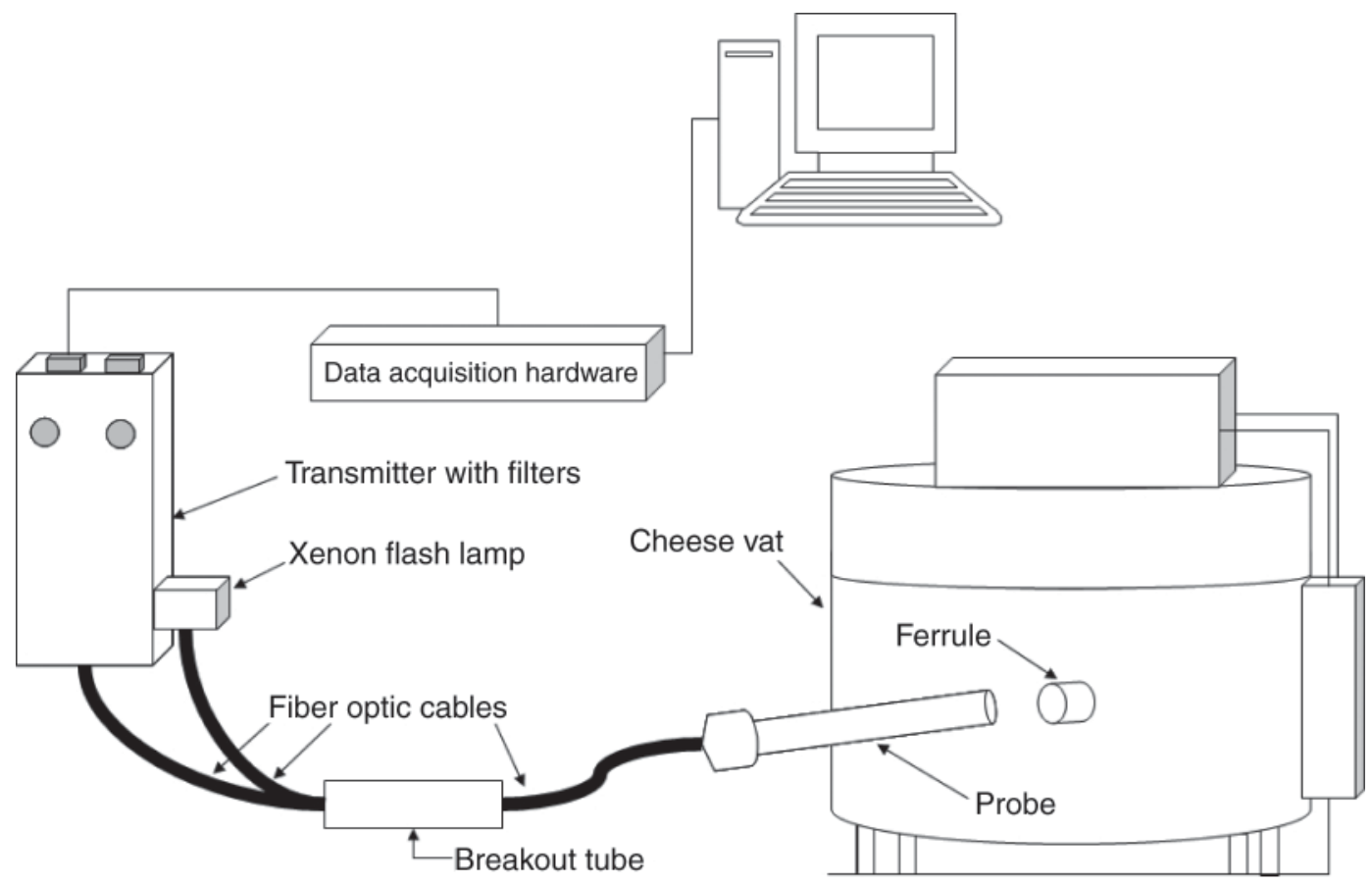

Figure 1. Schematic of the fluorescent measuring equipment used for monitoring milk coagulation and curd syneresis. 
et al. (2008b). During the stirring period 9 samples of curd/whey were removed at 10-min intervals for compositional analysis. An online sampler, as described by Mateo et al. (2009), was used to allow sampling to take place without interrupting stirring and without light interference in the sensor.

\section{Sampling and Compositional Analysis of Curd and Whey}

Sampling and chemical composition of curd and whey were carried out according to the procedure of Fagan et al. (2007a). Curd and whey were separated using a sieve (75- $\mu \mathrm{m}$ pore size). Three grams of curd and $5 \mathrm{~g}$ of whey were weighed into dishes using an analytical balance. The dishes were dried in a convection oven at $102^{\circ} \mathrm{C}$ until they reached a constant weight $(\sim 15 \mathrm{~h})$. Samples were analyzed in triplicate. The chemical composition of whey was also determined using a MilkoScan FT120 (Foss Electric). The curd yield on a wet basis $\left(C Y_{w b}\right)$ and curd yield on a dry basis $\left(C Y_{d b}\right)$ for each experiment were computed according to Fagan et al. (2007b).

\section{Data Analysis}

The sensor response during syneresis (i.e., from $t_{0}$ to $\left.t_{85}\right)$ was fitted to a first-order equation as follows:

$$
R_{t}=R_{\infty}+\left(R_{0}-R_{\infty}\right) e^{-k t},
$$

where $R_{t}$ is the fluorescence ratio at time $t(\min ), R_{\infty}$ is the fluorescence ratio at an infinite time, $R_{0}$ is the fluorescence ratio at $t_{0}$, and $k$ is the kinetic rate constant $\left(\min ^{-1}\right)$ for the sensor response during syneresis. The nonlinear regression (NLIN) procedure in the SAS statistical package (version 9.1; SAS Institute Inc., Cary, $\mathrm{NC}$ ) was used to determine the parameters $R_{\infty}, R_{0}$, and $k$. Where only the first $15 \mathrm{~min}$ of the sensor response during syneresis was fitted, a subscript 15 was used to denote this (i.e., $k_{15}$ ).

The significance of the relationships between parameters derived from the sensor response and syneresis indices was explored using the Proc CORR procedure in SAS.

Regression models for prediction of $C Y_{w b}, C Y_{d b}$, curd moisture $\left(C M_{85}\right)$, and whey TS $\left(W T S_{85}\right)$ content at the end of syneresis (i.e., $t_{85}$ ) were developed using the REG procedure. The Akaike information criterion (AIC) was used to select the best models for predicting $C Y_{w b}, C Y_{d b}, C M_{85}$, and $W T S_{85}$. The AIC allows for a comparison between models with a different number of variables.

\section{RESULTS AND DISCUSSION}

Compositional analysis of the milk showed consistency between batches. The average composition of the milk \pm the standard deviation was $4.24 \pm 0.08 \%, 3.31$ $\pm 0.03 \%$, and $13.3 \pm 0.1 \%$ for fat, protein, and TS contents, respectively.

\section{Response of Fluorescence Sensor to Varying Milk Solids Concentration}

Initially, the response of the different filter configurations to varying milk solids was investigated using reconstituted milk powder. Figure 2 confirmed that fluorescence increased linearly with solids content for each sensor $\left(\mathrm{R}^{2} \geq 0.99\right)$. Vitamin $\mathrm{A}$ and tryptophan are both associated with milk solids (i.e., lipids and $\mathrm{CN}$, respectively); hence, it would be expected that increasing the solids content of the milk would result in increased fluorescence. The milk powder would also contain riboflavin; hence, the increase in riboflavin fluorescence observed with increasing milk solids content. The linearity in the responses observed would be important in the development of this technique as a sensing technology. Interestingly, both Vitamin A and tryptophan fluorescence-based sensors increased by approximately $90 \%$ when milk solids content was increased from 2.5 to $11 \%$ (wt/wt), whereas the increase for riboflavin fluorescence was approximately $20 \%$ from 2.5 to $11 \%$ (wt/wt) milk solids content, suggesting the sensor was more sensitive to changes in vitamin $\mathrm{A}$ and tryptophan fluorescence than riboflavin fluorescence. This sensitivity provides a basis for the development of an online sensor technology based on this technology.

\section{Response of Fluorescence Sensors to Milk Coagulation}

The evolution of vitamin A, riboflavin, and tryptophan fluorescence during milk coagulation and syneresis is shown in Figure 3. During coagulation, the fluorescence of all 3 fluorophores increased by 5.7, 10.6, and $6.5 \%$ for vitamin A, riboflavin, and tryptophan fluorescence, respectively. These increases, as a percentage response, were smaller than the increase previously observed under similar conditions for a combined coagulation/syneresis control technology based on light backscatter of near-infrared light $(\sim 21 \pm 5 \%$; Fagan et al., 2007a). This suggests that the fluorescence-measuring system may be less sensitive to changes occurring in milk during coagulation than the light backscatter sensor. The light-scattering profile of enzymatically 


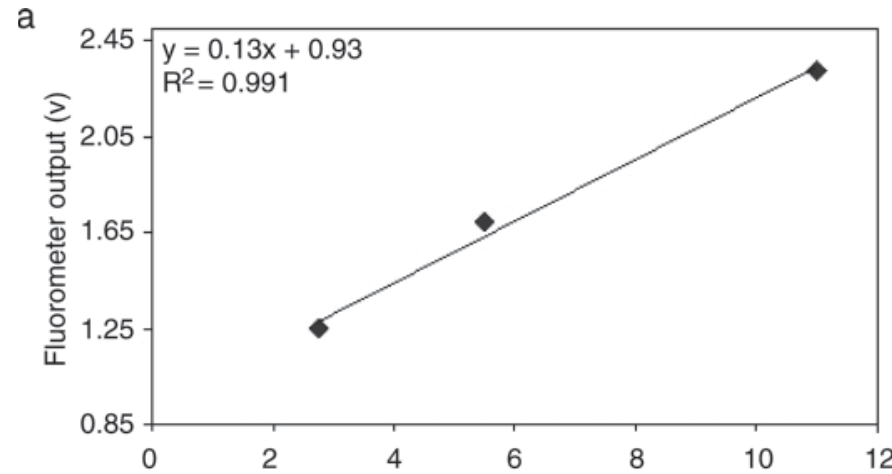

b

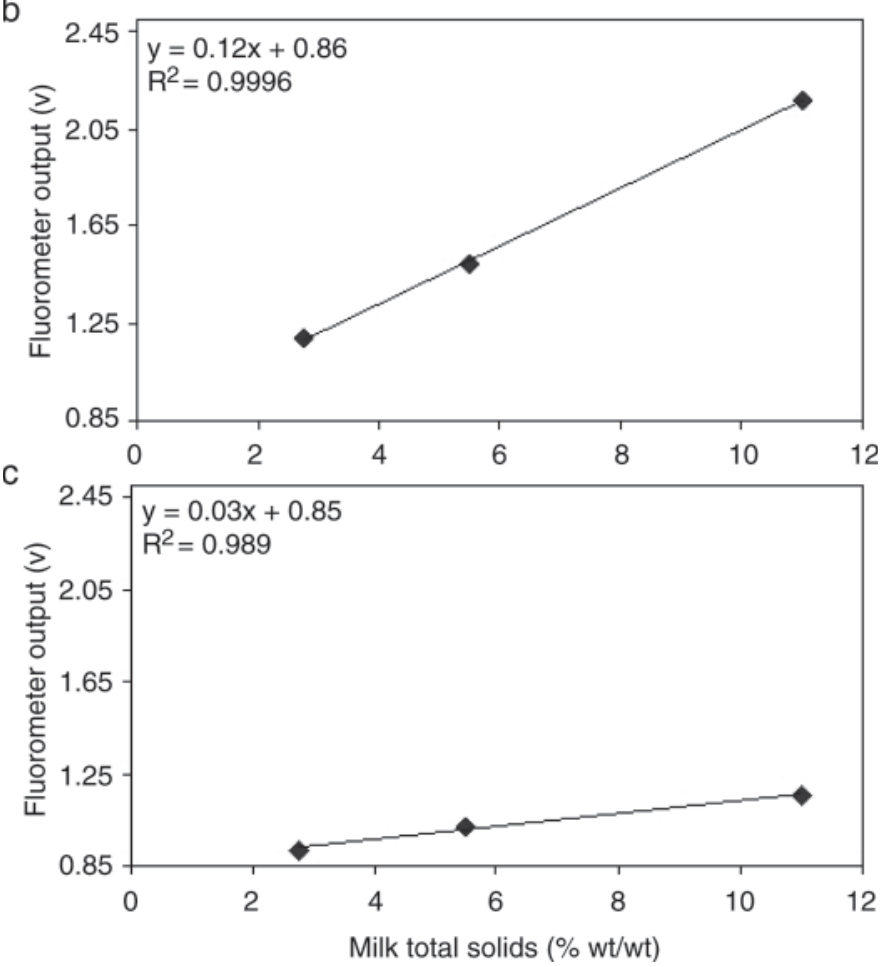

Figure 2. Effect of varying milk solids content on (a) vitamin A, (b) tryptophan, and (c) riboflavin fluorescence.

coagulated milk has previously been divided into 3 sections (i.e., induction, sigmoidal, and logarithmic), which related to the different stages of coagulation: namely, enzymatic hydrolysis of $\kappa-\mathrm{CN}$, aggregation of $\mathrm{CN}$ micelles, and curd firming induced by the decreased availability of crosslinking sites (Ustunol et al., 1991; Castillo et al., 2003). The fluorescence profiles of the 3 fluorophores during coagulation could, in general, be similarly divided.

Herbert et al. (1999) stated that the fluorescence properties of tryptophan were modified by changes in micelle structure and protein interactions induced by milk acidification or renneting. Previous research on the development of sensors for objective determination of cutting time have shown that the surroundings of
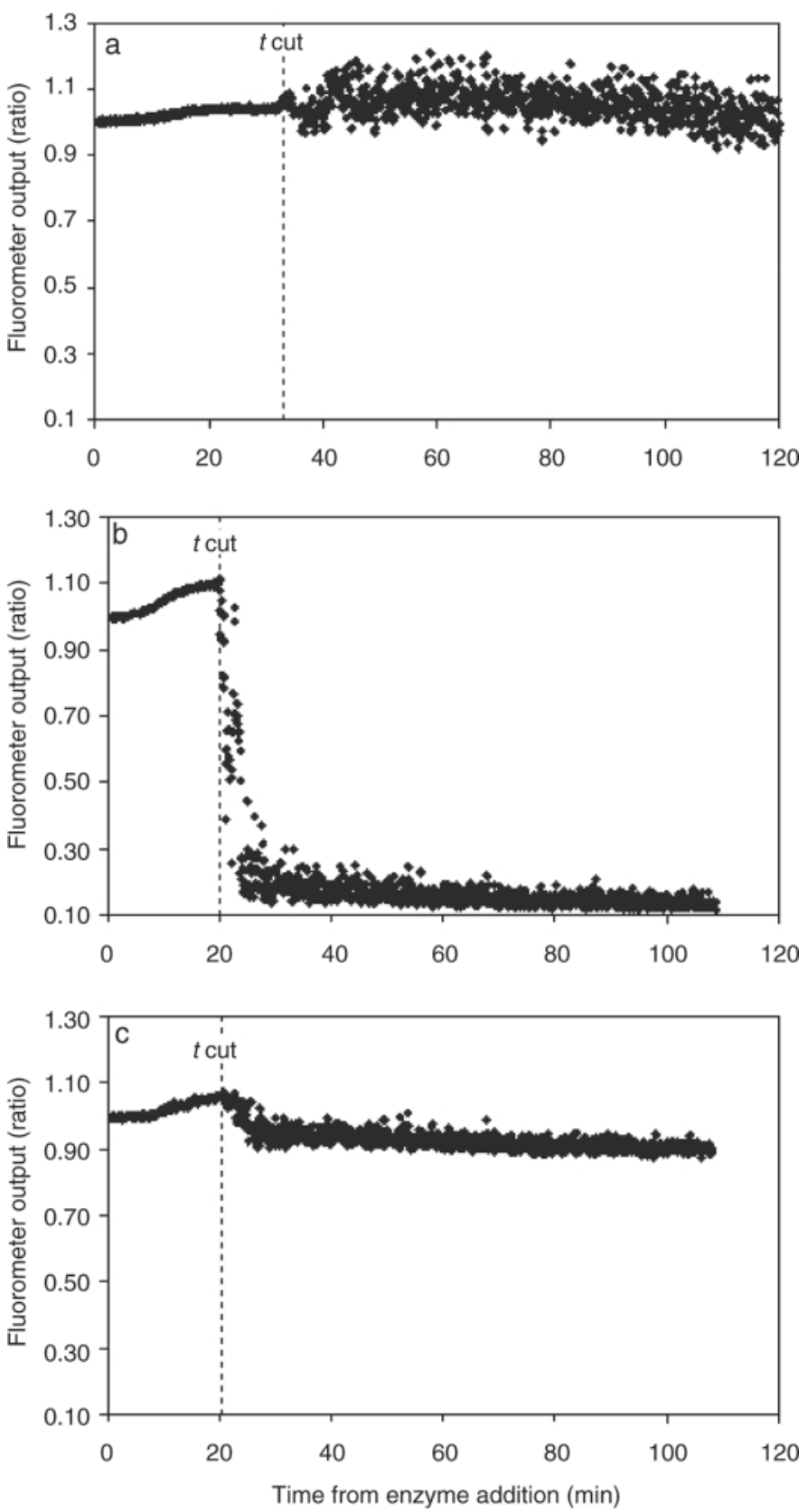

Figure 3. Evolution of (a) vitamin A, (b) tryptophan, and (c) riboflavin fluorescence during milk coagulation and syneresis. Each curve is an average of 3 replicates.

the time to the inflection point of the first derivative of the sensor profile $\left(t_{\max }\right)$ is dominated by aggregation kinetics (Payne et al., 1993; Castillo et al., 2006). Therefore the first derivative of the fluorescence profiles was calculated according to Fagan et al. (2007a). Whereas it was not possible to determine $t_{\max }$ for the majority of vitamin A trials, it was possible to calculate $t_{\max }$ for tryptophan and riboflavin trials (Figure 4). In particular, the inflection point obtained for tryptophan 
trials was very well defined, suggesting it may be an appropriate fluorescence-based technique for monitoring milk coagulation. The average $t_{\max }$ for tryptophan and riboflavin trials were $10.0 \pm 0.5 \mathrm{~min}$ and $10.2 \pm$ $1.7 \mathrm{~min}$, respectively. To compare the response of the fluorescence-based sensor to coagulation, 3 trials were carried out under the same processing conditions, using a light backscatter sensor technology (CoAguLite Model 5; Reflectronics Inc.) to monitor coagulation. This sensor can be used to determine $t_{\max }$ (Payne et al., 1993; Fagan et al., 2007a). A typical profile from the CoAguLite sensor is shown in Figure 5. The average $t_{\max }$, determined using the CoAguLite sensor was 10.8 $\pm 0.2 \mathrm{~min}$. The standard deviation between $t_{\max }$ derived for the riboflavin trials $(1.7 \mathrm{~min})$ is much higher than the standard deviation between the tryptophan and CoAguLite trials ( 0.5 and $0.2 \mathrm{~min}$ respectively). This is most likely due to the higher degree of scatter in the coagulation sensor response during riboflavin trials in comparison to the tryptophan and CoAguLite trials. The results also suggested that the fluorescence-based sensor detected the gel time slightly earlier than the light backscatter sensor; however, the difference between $t_{\max }$ values were not found to be significant.

\section{Response of Fluorescence Sensors to Curd Syneresis}

Syneresis was initiated by cutting the gel and, in the case of tryptophan (Figure 3b) and riboflavin (Figure 3c), this corresponded to an exponential decrease in the signal over time. However, for vitamin A fluorescence, the onset of syneresis resulted in a very high degree of scatter in the signal as well as a small overall decrease in signal intensity. The average decrease in signal intensity, calculated as the percent decrease from $t_{0}$ to $\mathrm{t}_{85}\left(\Delta \mathrm{R}_{\mathrm{syn}}\right)$, provides a measure of the magnitude of the decrease in the signal during syneresis. The $\Delta \mathrm{R}_{\mathrm{syn}}$ was 4.5, 88.7, and $16.1 \%$ for vitamin A, tryptophan, and riboflavin fluorescence respectively. For the previously demonstrated light backscatter syneresis sensor, the average $\Delta \mathrm{R}_{\text {syn }}$ was $59.4 \pm 12.0 \%$ (Fagan et al., 2007a). Fagan et al. (2007a) also suggested that if a sensor response is related to changes occurring during syneresis, it should most likely follow first-order kinetics, as the kinetics of syneresis follows first-order reactions. Therefore, the fluorometer responses during syneresis were fitted to Equation 1. The evolution of Vitamin A fluorescence during syneresis did not follow a first-order reaction. However, the results indicate that tryptophan and riboflavin fluorescence did, with the correlation coefficient between the experimentally recorded signal and signal fitted using Equation 1 being 0.86 and 0.66, respectively. These results suggest that only trypto-
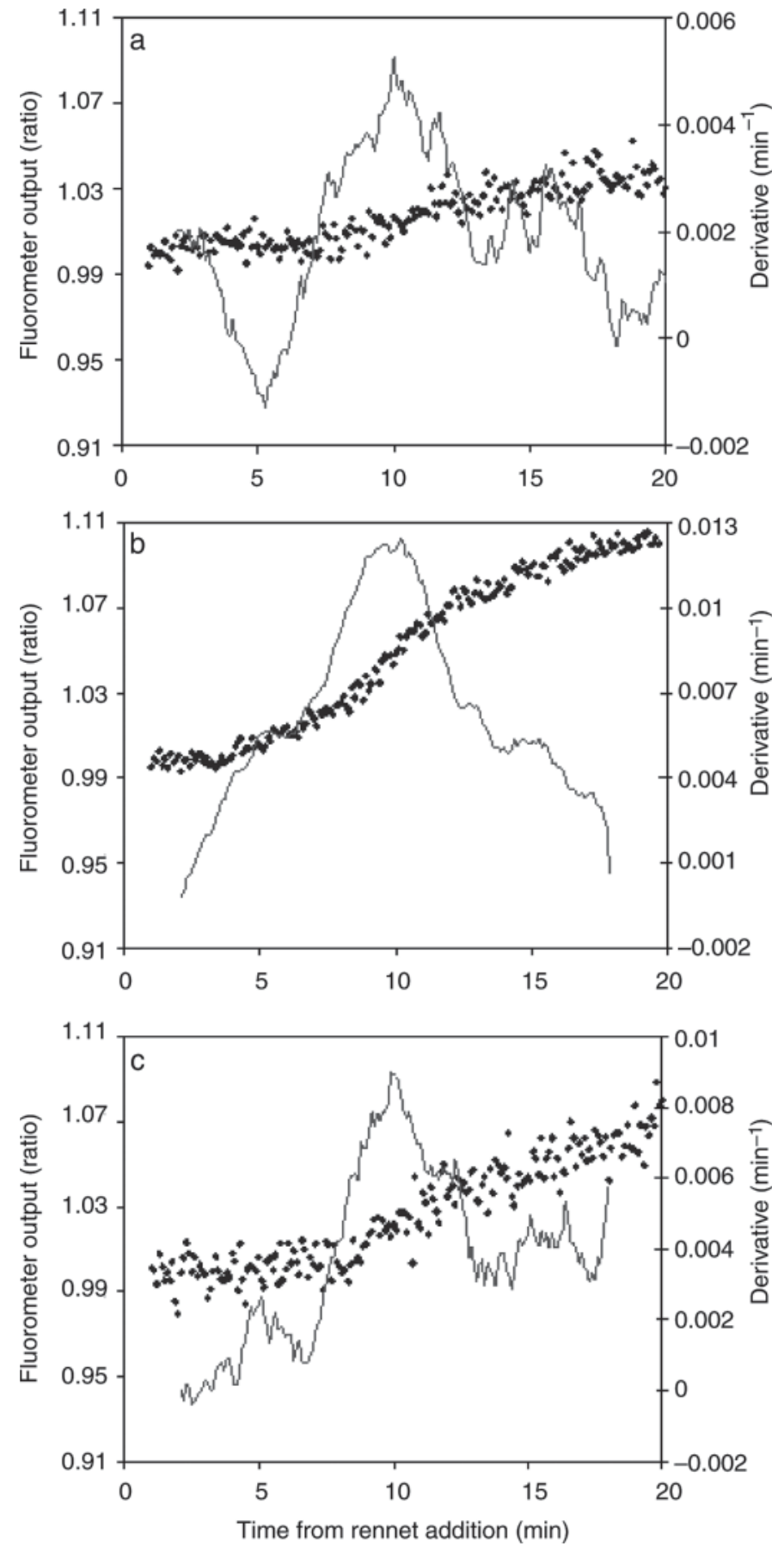

Figure 4. Evolution of (a) vitamin A, (b) tryptophan, and (c) riboflavin fluorescence during milk coagulation $(\bullet)$ and their corresponding first derivatives $(-)$ versus time.

phan and riboflavin fluorescence may be useful in the monitoring of curd syneresis and, hence, the results of the vitamin A trials will not be discussed further.

To determine if the sensor output was related to syneresis kinetics, the correlation between $R$ and indices 


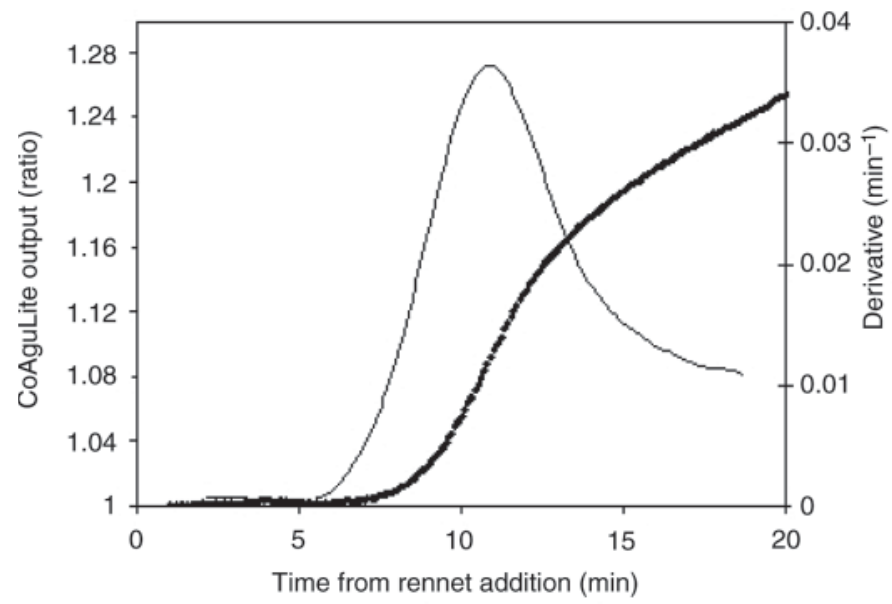

Figure 5. Light backscatter ratio profile during milk coagulation $\checkmark)$ and its corresponding first derivative $(-)$ versus time for the CoAguLite sensor (CoAguLite Model 5; Reflectronics Inc., Lexington, $\mathrm{KY})$.

of syneresis (i.e., curd moisture, whey TS, whey fat, and whey protein contents at each sampling point) was investigated. To obtain a representative value of $R$ at the sampling point, the last 5 measurements of $R$ before sampling $(30 \mathrm{~s})$ and the subsequent 5 measurements of $R(30 \mathrm{~s})$ were averaged. This value was denoted as $\hat{R}$. The correlations between $R_{\mathrm{t}}$ and the syneresis indices were also examined. The correlations between $\hat{R}, R_{t}$, and the syneresis indices are shown in Table 2. The tryptophan fluorescence signal $(\hat{R})$ has strong significant relationships with curd moisture content. The other strongest correlations were seen for the fitted riboflavin fluorescence signal $\left(R_{t}\right)$ and whey TS and whey fat content. In the case of tryptophan, $\hat{R}$ provided stronger correlations with syneresis indices than $R_{t}$, whereas in the case of riboflavin, the converse was found. Interestingly, the stronger correlations observed with $\hat{R}$ for tryptophan suggests that the level of scatter observed in the tryptophan signal may be acceptable. These results further indicate that the sensor monitoring changes in tryptophan and riboflavin fluorescence is sensitive to changes in curd moisture, whey TS, and whey fat content and could, therefore, be developed as a sensor for monitoring syneresis.

\section{Prediction of Syneresis Indices}

One- and two-parameter models for the prediction of 4 indices of syneresis, $C M_{85}, C Y_{w b}, C Y_{d b}$, and $W T S_{85}$ were developed. Table 3 shows the standardized regression coefficients for the models developed. The independent variables used included $\hat{R}, R_{t}, t_{c u t}, t_{\max }$, and $k_{15}$. This parameter was included because, in contrast to $\hat{R}$, $R_{t}$, or indeed $k$, it is known just 15 min after cutting and before the time point at which a prediction would be required.

In the case of the sensor detecting riboflavin fluorescence, the $C M_{85}$ (Equation 2), $C Y_{w b}$ (Equation 3), and $C Y_{d b}$ (Equation 4) models each contained a parameter derived from the sensor response during coagulation $\left(t_{c u t}, t_{\text {max }}\right)$ and syneresis $(\hat{R}, R)$. The $C M_{85}, C Y_{w b}$, and $C Y_{d b}$ models had SEP of $0.040 \%$ (wt/wt) $\left(\mathrm{R}^{2}=0.999\right)$, $0.273 \%\left(R^{2}=0.975\right)$, and $0.190 \%\left(R^{2}=0.987\right)$, respectively.

$$
\begin{gathered}
C M_{85}=334.7-161.1 \times R_{t}-584.0 \times t_{c u t}, \\
C Y_{w b}=473.7-294.3 \times R_{t}-9.1 \times t_{c u t}, \\
C Y_{d b}=39.3+4.4 \times \hat{R}-1.0 \times t_{\max } .
\end{gathered}
$$

Interestingly, $W T S_{85}$ could be predicted using just $k_{15}$ (Equation 5). This model predicted $W T S_{85}$ with an SEP of $0.002 \%$ (wt/wt; $\left.R^{2}=0.998\right)$.

$$
W T S_{85}=7.1+0.24 \times k_{15} .
$$

For the sensor detecting changes in tryptophan fluorescence, the AIC indicated that all 4 syneresis indices in 1-parameter models should be selected. The $C M_{85}$ (Equation 6), $C Y_{w b}$ (Equation 7), and $C Y_{d b}$ (Equation 8) models were developed using parameters derived from the sensor response during syneresis. Whereas

\begin{tabular}{|c|c|c|c|c|}
\hline \multirow[b]{2}{*}{ Item } & \multicolumn{2}{|c|}{ Tryptophan } & \multicolumn{2}{|c|}{ Riboflavin } \\
\hline & $\hat{R}$ & $R_{t}$ & $\hat{R}$ & $R_{t}$ \\
\hline Curd moisture & $0.864^{* * *}$ & $0.325^{* *}$ & $0.390^{* * *}$ & $0.519^{* * *}$ \\
\hline Whey TS & $0.696^{* * *}$ & $0.583^{* * *}$ & $0.271^{* *}$ & $0.874^{* * *}$ \\
\hline Whey fat & $0.569^{* * *}$ & $0.062^{\mathrm{NS}}$ & $0.323^{* *}$ & $0.811^{* * *}$ \\
\hline Whey protein & $0.380^{* * *}$ & $0.0015^{\mathrm{NS}}$ & $0.114^{\mathrm{ns}}$ & $0.317^{* *}$ \\
\hline
\end{tabular}
$C M_{85}$ was predicted using $\hat{R}[\mathrm{SEP}=0.007 \%(\mathrm{wt} / \mathrm{wt})$;

Table 2. Coefficient of determination $\left(\mathrm{R}^{2}\right)$ and significance between the average $(\hat{R})$ or predicted $\left[R_{t}\right.$ (Equation $1)$ fluorescence ratio at sampling and curd moisture, whey TS, whey fat, and whey protein content

*** $P<0.001 ; * * P<0.01 ; * P<0.05$. 
Table 3. Models for the prediction of final curd moisture content $\left(C M_{85}\right)$, curd yield on a wet basis $\left(C Y_{w b}\right)$, curd yield on a dry basis $\left(C Y_{d b}\right)$, and final whey TS content $\left(W T S_{85}\right)$, using parameters derived from the tryptophan and riboflavin sensor responses ${ }^{1}$

\begin{tabular}{llccc}
\hline Item & Fluorophore & Equation & $\beta_{1}$ & $\beta_{2}$ \\
\hline$C M_{85}[\%$ (wt/wt)] & Tryptophan & 2 & $-0.999^{*}$ & \\
$C Y_{w b}(\%)$ & Riboflavin & 3 & $-1.091^{*}$ & $-1.592^{*}$ \\
& Tryptophan & 4 & $0.981^{\mathrm{NS}}$ & \\
& Riboflavin & 5 & $-1.285^{\mathrm{NS}}$ & $-1.591^{\mathrm{NS}}$ \\
$W T S_{85}[\%(\mathrm{wt} / \mathrm{wt})]$ & Tryptophan & 6 & $0.982^{\mathrm{NS}}$ & \\
& Riboflavin & 7 & $0.342^{\mathrm{NS}}$ & $0.881^{\mathrm{NS}}$ \\
& Tryptophan & 8 & $0.992^{*}$ & \\
\hline
\end{tabular}

${ }^{1} \beta_{1}$ and $\beta_{2}=$ standardized regression coefficients.

$* P<0.05$.

$\left.\mathrm{R}^{2}=0.996\right], C Y_{w b}\left[\mathrm{SEP}=0.185 \%(\mathrm{wt} / \mathrm{wt}) ; \mathrm{R}^{2}=0.963\right]$ and $C Y_{d b}\left[\mathrm{SEP}=0.394 \%(\mathrm{wt} / \mathrm{wt}) ; \mathrm{R}^{2}=0.964\right]$ models could be predicted using $k_{15}$. Unlike Equation 5 , a coagulation parameter $\left(t_{\max }\right)$ was the parameter most useful for the predictions of WTS in trials where tryptophan was the tracer molecule [Equation 9; SEP $=0.0005 \%$ (wt/wt); $\left.\mathrm{R}^{2}=0.999\right]$.

$$
\begin{gathered}
C M_{85}=72.7-3.6 \times \hat{R}, \\
C Y_{w b}=24.0+3.8 \times k_{15}, \\
C Y_{d b}=51.3+8.2 \times k_{15}, \\
W T S=7.6+0.04 \times t_{\max } .
\end{gathered}
$$

Interestingly, Equations 7, 8, and 9 use only 1 parameter each, all of which are known 15 min after cutting at the latest. Although this is promising, it should also be noted that, after cutting, conditions in the vat were kept constant. For example, the temperature was kept constant. In the future, these models would possibly need to be adapted to take into account situations where parameters, such as temperature, are varied during syneresis.

Although these results from the developed models indicate that using milk fluorophores as tracer molecules for curd syneresis has potential, it must be noted that the number of samples used in this study was limited. The range of reference values was also small (Table 4). This limits the application of these models to use within the $C M_{85}, C Y_{w b}, C Y_{d b}$, and $W T S_{85}$ ranges observed. However, the results indicate that the technology has potential to be used in such an application and further investigation is warranted to confirm the findings of this study and to determine the sensitivity of the method.

\section{CONCLUSIONS}

The potential of vitamin A, tryptophan, and riboflavin to act as intrinsic tracers of syneresis was examined. A front-face fluorescence spectroscopy probe was installed in the wall of an 11-L cheese vat and the evolution of vitamin A, tryptophan, and riboflavin fluorescence during coagulation and syneresis was recorded. During coagulation, the vitamin A sensor response displayed a high degree of scatter and, overall, showed the smallest response to coagulation (5.7\%). Whereas the tryptophan and riboflavin sensors showed a slightly greater increase in signal intensity during coagulation, they also displayed a smaller amount of scatter, making it possible to extract $t_{\max }$ from their sensor profiles. The tryptophan and riboflavin sensor responses during syneresis were also found to correlate well with curd moisture and whey TS contents $(\mathrm{r}=0.86-0.96)$, whereas the vitamin A sensor did not correlate with either syneresis index. It was, therefore, concluded that tryptophan and riboflavin had potential to act as tracer molecules for milk coagulation and curd syneresis. The successful models for $C M_{85}, C Y_{w b}, C Y_{d b}$, and $W T S_{85}$, using parameters derived from the tryptophan and

Table 4. Range of experimental values obtained for curd yield on a wet basis $\left(C Y_{w b}\right)$, curd yield on a dry basis $\left(C Y_{d b}\right)$, curd moisture $\left(\mathrm{CM}_{85}\right)$ and whey TS $\left(\mathrm{WTS}_{85}\right)$ content at $85 \mathrm{~min}$ after the cutting time

\begin{tabular}{lcccc}
\hline Fluorophore & $\begin{array}{c}C M_{85} \\
{[(\mathrm{wt} / \mathrm{wt})]}\end{array}$ & $\begin{array}{c}C Y_{\mathrm{wb}} \\
(\%)\end{array}$ & $\begin{array}{c}C Y_{\mathrm{db}} \\
(\%)\end{array}$ & $\begin{array}{c}W T S_{85} \\
{[\%(\mathrm{wt} / \mathrm{wt})]}\end{array}$ \\
\hline Tryptophan & 0.24 & 2.1 & 4.59 & 0.04 \\
Riboflavin & 3.12 & 4.65 & 4.52 & 0.05 \\
\hline
\end{tabular}


riboflavin sensor responses, also support this conclusion. It was concluded that this study provides, for the first time, the basis for the development of a syneresis control technology based on the use of naturally present milk fluorophores. However, additional study is required to validate these findings under a wider range of processing conditions.

\section{ACKNOWLEDGMENTS}

The authors acknowledge Custom Sensors \& Technology (Fenton, MO) for providing the fluorescent measuring system. Funding for this research was provided by the Irish Department of Agriculture, Fisheries and Food (Dublin) through the Food Institutional Research Measure (FIRM) and by the US Department of Agriculture (Project NRI-USDA 2005-35503-15390).

\section{REFERENCES}

Andersen, C. M., and G. Mortensen. 2008. Fluorescence spectroscopy: A rapid tool for analyzing dairy products. J. Agric. Food Chem. 56:720-729.

Brinkmann, E., H. B. Oei, L. Dehne, R. Tiebach, and W. Baltes. 1993 Influence of heating on vitamin A content and vitamin A activity in liver and milk. Pages 44-48 in Vitamins and Other Supplements for Human and Animal Consumption. G. Flachowsky and R. Schubert, ed. Friedrich-Schiller-Universität, Jena, Germany

Castillo, M., J. A. Lucey, and F. A. Payne. 2006. The effect of temperature and inoculum concentration on rheological and light scatter properties of milk coagulated by a combination of bacterial fermentation and chymosin. Cottage cheese-type gels. Int. Dairy J. $16: 131-146$.

Castillo, M., F. Payne, and A. Shea. 2005a. Development of a combined sensor technology for monitoring coagulation and syneresis operations in cheese making. J. Dairy Sci. 88(Suppl. 1):142. (Abstr.)

Castillo, M., F. A. Payne, M. B. López, E. Ferrandini, and J. Laencina. 2005b. Preliminary evaluation of an optical method for modeling the dilution of fat globules in whey during syneresis of cheese curd. Appl. Eng. Agric. 21:265-268.

Castillo, M. Z., F. A. Payne, C. L. Hicks, J. S. Laencina, and M.-B. M. López. 2003. Modelling casein aggregation and curd firming in goats' milk from backscatter of infrared light. J. Dairy Res. 70:335-348.

Christensen, J., V. T. Povlsen, and J. Sørensen. 2003. Application of fluorescence spectroscopy and chemometrics in the evaluation of processed cheese during storage. J. Dairy Sci. 86:1101-1107.

Daviau, C., A. Pierre, M.-H. Famelart, H. Goudédranche, D. Jacob, M. Garnier, and J.-L. Maubois. 2000. Characterisation of whey drainage kinetics during soft cheese manufacture in relation with the physicochemical and technological factors, $\mathrm{pH}$ at renneting, casein concentration and ionic strength of milk. Lait 80:417-432.

Dufour, E., M. F. Devaux, P. Fortier, and S. Herbert. 2001. Delineation of the structure of soft cheeses at the molecular level by fluorescence spectroscopy-Relationship with texture. Int. Dairy J. $11: 465-473$.

Everard, C. D., D. J. O'Callaghan, M. J. Mateo, C. P. O'Donnell, M. Castillo, and F. A. Payne. 2008. Effects of cutting intensity and stirring speed on syneresis and curd losses during cheese manufacture. J. Dairy Sci. 91:2575-2582.
Fagan, C. C., M. Castillo, C. P. O'Donnell, D. J. O'Callaghan, and F. A. Payne. 2008a. On-line prediction of cheese making indices using backscatter of near infrared indices light. Int. Dairy J. 18:120128.

Fagan, C. C., M. Castillo, F. A. Payne, C. P. O'Donnell, M. Leedy, and D. J. O'Callaghan. 2007a. Novel online sensor technology for continuous monitoring of milk coagulation and whey separation in cheesemaking. J. Agric. Food Chem. 55:8836-8844.

Fagan, C. C., M. Castillo, F. A. Payne, C. P. O'Donnell, and D. J. O'Callaghan. 2007b. Effect of cutting time, temperature, and calcium on curd moisture, whey fat losses, and curd yield by response surface methodology. J. Dairy Sci. 90:4499-4512.

Fagan, C. C., C. J. Du, C. P. O'Donnell, M. Castillo, C. D. Everard, D. J. O'Callaghan, and F. A. Payne. 2008b. Application of image texture analysis for online determination of curd moisture and whey solids in a laboratory scale stirred cheese vat. J. Food Sci. 73:E250-E258.

Herbert, S. A. Riaublanc, B. Bouchet, D. J. Gallant, and E. Dufour. 1999. Fluorescence spectroscopy investigation of acid-or rennetinduced coagulation of milk. J. Dairy Sci. 82:2056-2062.

Herbert, S., N. M. Riou, M. F. Devaux, A. Riaublanc, B. Bouchet, D. J. Gallant, and E. Dufour. 2000. Monitoring the identity and the structure of soft cheeses by fluorescence spectroscopy. Lait 80:621-634.

Karoui, R., B. Martin, and É. Dufour. 2005. Potentiality of front-face fluorescence spectroscopy to determine the geographic origin of milks from the Haute-Loire department (France). Lait 85:223236.

Liu, X., and L. E. Metzger. 2007. Application of fluorescence spectroscopy for monitoring changes in nonfat dry milk during storage. J. Dairy Sci. 90:24-37.

Mateo, M. J., D. J. O'Callaghan, C. D. Everard, C. C. Fagan, M. Castillo, F. A. Payne, and C. P. O'Donnell. 2009. Influence of curd cutting programme and stirring speed on the prediction of syneresis indices in cheese-making using NIR light backscatter. Food Sci. Technol. 42:950-955.

Miquel Becker, E., J. Christensen, C. S. Frederiksen, and V. K. Haugaard. 2003. Front-face fluorescence spectroscopy and chemometrics in analysis of yogurt: Rapid analysis of riboflavin. J. Dairy Sci. 86:2508-2515.

Öste, R., M. Jägerstad, and I. Andersson. 1997. Vitamins in milk and milk products. Pages 347-402 in Advanced Dairy Chemistry: Volume 3: Lactose, Water, Salts and Vitamins. P. F. Fox, ed. Chapman \& Hall, London, UK.

Payne, F. A.. C. L. Hicks, and P. S. Shen. 1993. Predicting optimal cutting time of coagulating milk using diffuse reflectance. J. Dairy Sci. 76:48-61.

Pearse, M. J., and A. G. Mackinlay. 1989. Biochemical aspects of syneresis: A review. J. Dairy Sci. 72:1401-1407.

Talens, C., D. J. O'Callaghan, C. D. Everard, C. C. Fagan, M. Castillo, F. A. Payne, and C. P. O'Donnell. 2009. Evaluation of an improved tracer method to monitor cheese curd syneresis at varying milk fat levels in a cheese vat. Milchwissenschaft 64:161-164.

Ustunol, Z., C. L. Hicks, and F. A. Payne. 1991. Diffuse reflectance profiles of 8 milk-clotting enzyme preparations. J. Food Sci. 56:411-415.

Wagner, K., H. Graf, G. Schaarmann, and G. Flachowsky. 1993. Influence of cooking and microwave treatment on the vitamin A content of milk. Pages 49-52 in Vitamins and Other Supplements for Human and Animal Consumption. G. Flachowsky and R. Schubert, ed. Friedrich-Schiller-Universität, Jena, Germany

Wold, J. P., K. Jørgensen, and F. Lundby. 2002. Nondestructive measurement of light-induced oxidation in dairy products by fluorescence spectroscopy and imaging. J. Dairy Sci. 85:1693-1704.

Zahar, M., D. E. Smith, and F. Martin. 1995. Vitamin A distribution among fat globule core, fat globule membrane, and serum fraction in milk. J. Dairy Sci. 78:498-505. 